DOI 10.35381/cm.v6i10.131

\title{
Demografía y población de época colonial
}

\section{Demography and colonial era population}

\author{
José Luis Vinueza Moreno \\ jose.vinueza@gmail.com \\ Universidad Central del Ecuador \\ Ecuador \\ https://orcid.org/0000-0001-5468-6472
}

Recibido: 13 de marzo del 2019

Aprobado: 06 de junio del 2019

\section{RESUMEN}

El presente estudio está orientado en analizar la demografía en la sociedad colonial de América y algo más, según diversos factores y reflexiones de algunos historiadores. Mostrando interpretaciones de aquel suceso colonial vivido por nuestra América. Para ello, fueron seleccionados documentos como el de Carlos Malamud, la metodología empleada para la reconstrucción de los acontecimientos e interpretación históricas de la información fue las búsqueda a través de distintas plataformas de almacenamiento de información iniciando con palabras claves relacionadas con el descubrimiento de américa lo cual garantizó un compendio de abordaje y distintas voces reflexionando lo ocurrido aquel 1492 y el pasado común que nos une, para así darle valoración a ciertos tópicos que aún se encuentran arraigado mediante el tabú y el prejuicio. Además esta estudio busca que exista un acercamiento y gran valoración a los hispanos que aun España mantiene para su resguardo sobre los sucesos perpetrados en tiempos de colonización.

Descriptores: Demografía, Descubrimiento de América, sociedad colonial.

\section{ABSTRACT}

The present study is aimed at analyzing demographics in the Colonial Society of America and something else, according to various factors and reflections of some historians. Showing interpretations of that colonial event lived by our America. To this end, the documents were selected such as that of Carlos Malamud, the methodology 


\section{CIENCIAMATRIA \\ Revista Interdisciplinaria de Humanidades, Educación, Ciencia y Tecnología \\ Año Vl. Vol. VI. №10. Enero - Julio 2020 \\ Hecho el depósito de ley: pp201602FA4721 \\ ISSN-L: 2542-3029; ISSN: 2610-802X \\ Universidad Nacional Experimental Francisco de Miranda (UNEFM). Santa Ana de Coro. Venezuela}

José Luis Vinueza Moreno

used for the reconstruction of the historical events and interpretation of the information was the search through different storage platforms of Information initiating with key words related to the discovery of America which guaranteed a compendium of boarding and different voices reflecting what happened that 1492 and the common past that unites us, in order to give valuation to certain topics that are still Entrenched by Taboo and prejudice. In addition, this study seeks that there is an approach and great valuation to Hispanics that even Spain maintains for its protection on the events perpetrated in times of colonization.

Descriptors: Demography, Discovery of America, Colonial Society.

\section{A MODO DE INTRODUCCIÓN}

Este estudio aborda el impacto demográfico visto desde otra óptica según lo presenta que cobró vida en el proceso colonial, la trata negrera la cual es dimanada del primer rasgo y finalmente se esboza los elementos que orbitan en la constitución de la sociedad de los españoles y los aspectos que dan conformidad a la sociedad de los aborígenes del Nuevo Mundo.

Tocante al choque demográfico surge una pregunta interesante y sencilla ¿cuál era el tamaño de la población americana en el momento de la conquista? Por pletóricas razones como: los censos no eran tan precisos, había manipulación e intereses detrás de estos, por lo que en la actualidad aún se discute la cifra, la cual ronda entre los 50 y 100 millones de habitantes en el continente, estudios más conservadores apunta sobre la primera y otras investigaciones que sin timidez se acerca a la segunda.

Bajo la misma urdimbre hay unos aspectos inmersos en el choque demográfico entre Europa y el Nuevo Mundo, la mortandad que arribó a las Antillas Mayores y Menores y en tierra firme no debe ser vista únicamente bajo el enfoque de la arena de la conflagración, sino que factores como el epidemiológico, inanición, "a esto se le suma la llamada desgana vital, una situación de crisis anímica causada por el brutal choque cultural de la conquista y la ruptura de las formas tradicionales de los aborígenes de vivir y producir (...)" Brizuela (2013). 


\section{CIENCIAMATRIA \\ Revista Interdisciplinaria de Humanidades, Educación, Ciencia y Tecnología \\ Año Vl. Vol. VI. №10. Enero - Julio 2020 \\ Hecho el depósito de ley: pp201602FA4721 \\ ISSN-L: 2542-3029; ISSN: 2610-802X \\ Universidad Nacional Experimental Francisco de Miranda (UNEFM). Santa Ana de Coro. Venezuela}

José Luis Vinueza Moreno

Respecto al primer aspecto es asaz pertinente citar a la profesora Vargas "no es verdad la afirmación de la superioridad de las armas europeas, (...). Lo cierto parece haber sido, muy al contrario, que las armas indígenas: arcos, flechas, jabalinas y macanas eran superiores a los arcabuces europeos, pues en el tiempo que tardaban los arcabuceros en cargar sus armas, los/as flecheros/as indios/as lanzaban cientos de flechas, las más de las veces con acierto" Malamud (2010).

\section{Resistencia o invasión}

La reticencia que emerge ahora es ¿cómo los españoles vencieron, entonces, a los aborígenes americanos? La respuesta radica en la guisa antagónica de ambos bando de concebir la guerra.

Glosa Vargas lo siguiente "Mientras que para los invasores la guerra era pensada como de exterminio, vale decir, acabar con todos los enemigos si era posible, apoderarse de sus riquezas y territorios, y someter y esclavizar por la fuerza a los/as vencidos/as, para los indígenas consistía en una forma de relación social, cuya realización se cumplía con una serie de normas que incluían, entre otras, pausas entre batallas. A cada batalla ganada o perdida seguía un reordenamiento de las tácticas y un reposo de los/as combatientes" Malamud (2010).

El pretérito párrafo arroja luz de que no fueron las flechas nuestra americanas las que se hallaban en desventajas ante las espadas y arcabuces europeos, esta misma razón no nos puede llevar a que la causa única de la muerte de nuestros aborígenes haya sido el encuentro bélico, sino la contribución en gran medida de los aspectos mencionados previamente que acompañaron a este rasgo. En cuanto a una de las características que acompaño a la beligerancia está el facto epidemiológico que lo expone con minuciosidad el profesor argentino Carlos Malamud.

\section{Enfermedades que se propagaron}


Apoyándose en una obra de Sherburne Cook publicada en 1947, adjunta cuadros en su libro que exponen datos interesantes como que la viruela ya se conocía en América y había ocasionado estragos en unos períodos determinados en el imperio azteca, presenta el caso del sarampión, cuya enfermedad diezmo de 1519-1528 el 35\% de la población, es uno de los datos más alarmantes y como ese muestra varios datos más.

Otro cuadro de posibles pandemias en América, por enfermedad devela los siguientes casos: a) gripe 1494-1514, b) la viruela presenta dos brotes en el mismo siglo XVI el primero de 1519-1528 y el segundo; 1576-1591 c) tifus presentó tres manifestaciones entre mediados del siglo XV y mediados del XVI y d) sarampión con cinco vástagos en menos de un siglo. Se podría considerar este último como uno de los más agresivos.

\section{Los alimentos en tiempos coloniales}

Lo que respecta a la producción de alimentos, cuyo agente es relevante en la colisión demográfica, Sherburne Cook suele calcularlo en base de los habitantes por kilómetros cuadrados.

Sus fuentes de información concernientes a la búsqueda de la cantidad de habitantes indígenas son John Durand, Esther Boserup, Woodrow Borah, el antes mencionado Cook, Diez de San Miguel, entre varios otros que le ayudaron a bosquejar la panorámica demográfica del proceso colonial del Nuevo Mundo.

Además del aspecto censal el autor aporta que "La recuperación de la población indígena fue lenta, desigual e irregular, con importantes variaciones regionales. A mediados del siglo XVI, unos 7.000 .000 de personas poblaban las Indias, de los cuales 5 millones eran indios (un 71\%), 735.000 negros (10,5\%), 659.000 blancos (9,5\%), mientras que el otro 9\% lo formaban mestizos (400.000) y mulatos (240.000)" Brizuela (2013).

\section{De la trata negrera}


El siguiente eje, la trata negrera, tiene un rasgo que es poco conocido y algunos autores omiten de la historia colonial y que es necesario vislumbrar. La provechosa empresa de la esclavitud con personas negras lo emprenden los portugueses y no los españoles, porque son los primeros los que tienen contacto con África del norte y van relacionándose con ellos durante mucho tiempo y en el continente africano existía unas grandes civilizaciones, sobre todo en el África occidental había grandes reinos que se fueron sucediendo unos a otros. Los conocidos reinos del bosque, que no eran otra cosa que grandes civilizaciones, que florecieron en los siglos XI, XII y XIII.

África estaba en su magnificencia de costa a costa porque reinos como Zimbabue solazaba de una riqueza cultural y económica gracias al tratamiento con países asiáticos por medio del océano Índico y por la costa atlántica estaban reinos como Benín, el cual llegó a tener el nivel más alto de civilización para ese entonces, los reinos Yorubas, de Ghana y muchos otros. Es pertinente hacer esa breve síntesis de status quo de reinos y civilizaciones que se localizaban en África, porque siempre se ha percibido a ese vasto continente como atrasado y ha incidido bastante la influencia de la visión eurocentrista en América.

Con estas desarrolladas civilizaciones es que el reino católico de Portugal va a estrechar lazos. Inclusive es menester memorar que en sus inicios la relación que tuvo la Corona portuguesa con estas avanzadas culturas fue netamente intelectual, donde iba una pléyade de letrados de Benín a Portugal y viceversa, también existía un comercio bilateral de materias primas. Toda esta correlación irá trocándose cuando los españoles empiecen a necesitar mano de obra barata para sus trabajos en el Nuevo Mundo porque la población indígena estaba siendo diezmada por múltiples razones, ya algunas expuestas en páginas previas.

\section{Masificación de la agricultura y la economía mediante el sometimiento}


Esto coincide con las plantaciones de azúcar que es la nueva compañía que arrancan los portugueses en el Brasil y comprenden que la población indígena no les serviría para este tipo de trabajo forzado, claro está, después de un extenso proceso de represión y persecución. Por lo tanto inician un comercio de esclavos gradual con las culturas africanas que los poseían. Esta característica de que las culturas africanas tuvieran esclavos es muy distinta al fundamento europeo. Los reinos africanos se hacían de los esclavos al mismo modo que lo hacían los griegos o los romanos, se esclavizaban aquellos que perdían una guerra o que no podían pagar alguna deuda, por un lado, la esclavitud era una condición temporal y estaba sujeta a ser comprada y por el otro, no era particularmente con un pueblo sino con una situación histórica. No se pretende negar el comercio que heredaron los africanos de los árabes, quienes ya habían hecho de esta condición un negocio, empero, en África era particular y a través de los árabes.

Vinculando estas ideas al aspecto que nos ocupa, la trata negrera, son los portugueses quienes llegan a los españoles ver en los negros esclavizados los brazos baratos para la explotación de las colonias y el enriquecimiento de la metrópolis. Pues, lo que pone de manifiesto que son los negros quienes culminarán los trabajos forzados que los aborígenes habían iniciado en sus propias tierras.

Un interesantísimo aporte que Malamud realiza acerca de la visión de la trata negrera entre ambas potencias europeas es que "En 1517, Carlos I estableció un sistema de concesiones a particulares para la introducción y venta de esclavos negros, si bien sólo a partir de 1528 la trata con destino a Indias comenzó a ser importante. El rey exigía el pago de una licencia para introducir esclavos en sus colonias y se limitó la importación a 75.000 personas anuales hasta fines del siglo XVI", Brizuela (2013).

No obstante, se puede contrastar la relación de la esclavitud que tenía la Corona española con respecto a la portuguesa con lo siguiente "en 1595, los portugueses recibieron el asiento para comerciar esclavos africanos con América. De este modo, mercaderes portugueses y alemanes desarrollaron el comercio negrero entre África y 
algunos puertos americanos, como Veracruz, Portobelo y Cartagena de Indias. Entre 1550 y 1650 se introdujeron en las colonias lusas del Brasil más de 300.000 esclavos", Brizuela (2013).

Para departir sobre algo tan significante como la complexión de la sociedad española es imperioso conocer que el sistema económico que regía a las grandes potencias del planeta era el mercantilismo, el cual se basa en la explotación de minerales auríferos, acumulación de los mismos y la explotación y extracción de materias primas. Teniendo conocimiento de esto podemos fácilmente discernir porqué la cimentación de grandes villas imperiales y majestuosas ciudades como la de Potosí, Durango, Zacatecas, Huancavelica, que a su vez eran centros mineros.

Los puertos también eran imprescindibles para la exportación de las materias primas, eso también dilucida porque las principales ciudades estaban ubicadas cerca de las costas.

Las ciudades como lo dice Malamud eran centros de relación social, y continúan los vestigios de ellas en la actualidad. Veamos que "Las ciudades se estructuraron en torno a la Plaza Mayor. Allí solían estar el cabildo, la iglesia y los edificios públicos. En su proximidad se levantaban las casas de los encomenderos y los vecinos más poderosos. La plaza era el lugar de celebración del mercado y allí también tenían lugar los festejos y actos más diversos, en los que participaba toda la población", Brizuela (2013).

Había profundas diferencias entre los que pechaban y los que no, es decir; entre los que tributaban sus impuestos y aquéllos que no lo hacían, por lo que denota ya una escisión de clase dentro de la misma casta española que residía en el Nuevo Mundo. Las mujeres eran vistas como si fuesen menores de edad, ya que de solteras dependían de sus padres y al casarse sus esposos les mantenían, esto era indiferentemente a la casta española que perteneciesen. Dicho en palabras de la profesora Vargas "De ser seres combativos y luchadores, relativamente libres, las mujeres pasaron a ser durante la colonia, legalmente, objetos de propiedad, primero de 
sus padres; luego, de sus esposos y, finalmente, de sus hermanos y de sus hijos varones", Malamud (2010).

\section{El proceso transcultural de los aborígenes}

Los aborígenes evidentemente empezaron a ser adoptar costumbres y culturas externas y los artesanos fueron los principales motores de aculturación. No huelga señalar que el comercio marítimo aportaba también una riqueza cultural a todo lo que estaba erigiéndose en el continente americano, y este a su vez aportaba nuevos cánones de cultura e idiosincrasia a otros continentes, por cuanto por medio de los negociones transoceánicos no sólo viajaba la mercancía, los minerales y vidas humanas sino que imanado e todo esto iba una rica cultura milenaria haciendo aportes.

Muchas de las sociedades de los indios, antes de la llegada de los españoles, eran matriarcales y horizontales, y no se vea como una estrategia adaptativa para sobrevivir en la pobreza, sino más bien como singularidades de las familias extendidas indígenas que conforman organizaciones, complejas e insustituibles, que garantizan la vida humana y ratifican la vida social. Hubo una evolución paulatina de los modos de vida de nuestras culturas ancestrales, que algunos autores, tratan de concebir como taras atávicas que se vienen heredando cuando realmente son riquezas milenarias que deben ser rescatadas.

En el mismo orden ideas los aborígenes colaboraron en el aparataje del sistema que ya se estaba articulando. Algunos colaboraron como corregidores, vale decir; ayudantes o intérpretes, alcaldes o alguaciles de indios, y su función era "gobernar los vastos territorios rurales en que se sentaban las comunidades indígenas, administrar justicia en nombre del rey y cobrar el tributo, que solía ser recogido por los caciques", Brizuela (2013). Incluso para Guillermo Céspedes este sistema hubiese sido factible pero lo entorpeció la extralimitación y el atropello en el trabajo forzoso a los aborígenes americanos. En síntesis, se develó como el choque demográfico entre el Viejo y el Nuevo Mundo causaron estragos en bienes materiales y humanos. 
El diezmo de este último, por múltiples factores, diversos vástagos epidemiológicos y persecución constante, provocó como rasgo consustancial al proceso colonial la trata negrera en nuestro continente para reemplazar los brazos baratos indígenas que casi no se encontraban porque habían sido mermados unos y otros se internaron en lugares como selvas inexplorables para ese entonces. La trata negrera fue tratada de una manera breve, empero, con detalles que sincerara una panorámica del contexto social de la época y su fuerte vinculación con la Corona portuguesa como pionera de este eje embrionario para la instalación del motor desarrollista de las metrópolis europeas.

\section{Proceso colonial en América (Malamud)}

El profesor Carlos Malamud en su obra con lo que es menester, la delimitación y esclarecimiento de términos que han incidido tanto en nuestra historia y que franqueado cinco siglos continua aún sobre el tapete que es el "Descubrimiento de América" o el asimismo apellidado "Encuentro de dos mundos", a pesar de que se refiere al mismo evento temporo espacial, Malamud expone que ambos epígrafes no resultan útiles para la aplicación científica. Sencillamente porque en el primero; América (Abya Yala) había sido descubierta y poblada por otros moradores, y no precisamente europeos, sino asiáticos, y el segundo; debido que fueron mucho más de dos mundos los que se encontraron o embistieron como lo menciona el autor.

Malamud elabora un replanteamiento en su investigación, referente a la llegada de los europeos a nuestro continente. El papel que jugó Europa fue preponderante, porque no fue la península ibérica los que emprendieron esta empresa sino que estuvieron involucrados varios reinados de Europa, en los que se amalgamaron tecnologías, monarquías, dinero para que emergiera tan ambiciosa empresa, un factor que varios otros autores no hacen reminiscencia colocando como protagonistas sólo a españoles y portugueses.

El avance tecnológico cobra vital importancia en este proyecto. Es fundamental evocar la invasión al sur del territorio español por parte el imperio turco otomano, entre el año 
711 y el año 1492 d.n.e.; tal invasión le había costado a España un atraso con respecto con otras naciones, como Francia e Inglaterra, ya que no tenía salida al mar Mediterráneo.

La zona exclusiva de comercio que tenía la Corona española en este mar fue usurpada por los turcos otomanos al empoderarse de los reinos al sur, como Granada, e instalar el califato de Córdova; paralelamente a la existencia de fortísimos conflictos de orden religioso, puesto que España y casi la totalidad de su población eran católicos, que debían luchar con el dogma de los musulmanes y el Corán.

¿No huelga preguntarse por qué no fue la Corona portuguesa la que emprendió los viajes al Nuevo Mundo, puesto que tenía más posibilidades con respecto a la España invadida y asediada por el Imperio Turco?

A pesar que la Corona lusa era un reino que por antonomasia debe ser de navegantes y exploradores por su posición geográfica, donde es el océano atlántico quien explícitamente baña sus litorales, lo eximio fue su forma de navegación, cabotaje, consta en la navegación o tráfico comercial hecho a lo largo de la costa de un país.

África y Asia, estos dos vastos continentes fueron los primeros en experimentar esta aventura náutica lusitana y esto no es por otra cosa que no sea por su contigüidad con el continente europeo.

A diferencia de España que le habían usurpado su única salida al mar Mediterráneo, zona estratégica para aperturas del negocio con África, continente que ya había sido víctima de anhelos imperiales desde los albores de 1434 cuando naves portuguesas rodearon al Cabo Bojador, bajo el afán de Enrique El Navegante, hijo del Rey Juan I de Portugal, de extender el minúsculo territorio portugués. Para 1480 la totalidad de la costa de Guinea era conocida por los portugueses.

La Corona española estaba quedando por fuera de la repartición del pastel, por lo que se tuvo que expeler a la conquista del mar abierto para encontrar nuevas rutas que la condujeran a Asia y es en este episodio historiográfico que tomará protagonismo el Genovés Cristóbal Colón y en un contexto de una España mancillada por los estragos 
de una invasión que le costó casi ocho siglos de lucha para repeler al invasor, en la que Colón participó desde 1482 de forma directa como soldado del incipiente matrimonio de los reinos de Castilla y Aragón para sacar a los invasores. Esto contribuyó exponencialmente en el financiamiento de los viajes harto conocidos en nuestra historia.

Colón en su primer viaje no lleva de vuelta a Europa ni oro ni especias, pero como lo menciona el profesor Malamud era "el feliz portador de una noticia revolucionaria: su teoría que se podía circunnavegar el globo navegando mar adentro hacia el oeste se presentaba como correcta".

Juan II de Portugal se entera de los avances que están teniendo los Reyes Católicos de Castilla y Aragón debido a una tormenta que sufrió Colon y debió arribar en Lisboa. Esto lleva a unos nuevos tratados: La bula Papal de Alejandro VI, en junio de 1493, que después fue sustituida por el Tratado de Tordesillas en mayo 1494, hoy Valladolid ubicada en el centro norte de España. Sin olvidar la importancia del Tratado de Santa Fe el cual concedía a Colón los títulos de almirante, virrey y gobernador general de todos los territorios que descubriera o ganase durante su vida, así como la décima parte de todos los beneficios obtenidos. También se le concedió un diezmo de todas las mercaderías que hallase, ganase y hubiese en los lugares conquistados.

Ulterior a las dificultades económicas por la que transitaba la Corona Española, amén del motín liderado por Francisco Roldán en La Española, acusando a Colón de mal gobierno, termina el periplo del Almirante y también la grandeza con la que fue visto llegando el momento de arrojar luz sobre otros conquistadores. En el Perú el emperador inca Atahualpa trató de aplacar a Pizarro llenando un cuarto entero de oro y dos de plata. No bastó para salvar su vida ni la del imperio del sol. El español lo degolló y se lanzó sobre el Cuzco a golpes de hacha. Francisco Pizarro, un analfabeto que había sido criador de cerdos, rompió los adornos de las ceremonias sagradas, las joyas antiguas, los dioses, los brazaletes, las diademas de la fiesta. Todo se convirtió en barras de oro español para pagar la deuda de la Corona. 
Buscaban oro en las lagunas, en las selvas, en el fondo de los volcanes. Buscando oro, llegó Núñez de Balboa al Pacífico y Pedro de Alvarado a Guatemala. Buscando oro, Pedro de Valdivia atravesó el desierto costero del Perú hasta Chile. Y Lope de Aguirre enloqueció tratando de hallar aquella ciudad de El Dorado que nunca aparecía.

Hernán Cortés se embarcó hacia México y destruyó la gran ciudad de Tenochtitlán en un tiempo record de treinta años. Existen dos caras de la conquista. Expone el autor una fue la gloriosa, la que mira la colosal tarea de los conquistadores, hombres de coraje reconocido capaces de salvar cuanto obstáculo se les pusiera por delante. Hay que tener en cuenta que América tiene una superficie ochenta veces mayor que la de España y que todo el episodio de la conquista fue realizado por un número no mayor a 10.000 peninsulares".

La otra cara, explica Malamud, fue la de la tragedia, la del drama continuo y permanente de los pueblos dominados, de los indios esclavizados, de las culturas destruidas, de la catástrofe demográfica. $\mathrm{Y}$ así podríamos seguir, buscando las múltiples facetas de la conquista. Añade el autor argentino que la conquista no puede reducirse a ninguna de ellas por separado. Fue un acto más de la expansión humana, con sus luces y sus sombras, con sus grandezas y sus miserias, que cambió definitivamente la realidad del Nuevo Mundo.

Juan de la Cosa que había estado con Colón en La Española y tenía experiencia en el Caribe, creo factorías para negociar aborígenes, esclavizarlos y saquearles el oro. Tuvo mayor incidencia en la región comprendida desde las costas de la bahía de Cartagena, conocida como la Guajira actualmente, hasta el Golfo de Urabá, la zona más austral del mar Caribe localizado al este de la frontera entre Colombia y Panamá. Cosa tuvo que exponerse a la actitud beligerante que poseían los aborígenes autóctonos de esos lares y que posteriormente moriría a manos de ellos por la ambición de su propia empresa.

Para 1508 se perpetra una Junta en Burgos para establecer asuntos limítrofes, sus fronteras serían las siguientes: Urabá (desde el cabo de la Vela hasta el golfo de Urabá) y Veragua (desde el golfo de Urabá hasta Nicaragua), y llevar a cabo la consolidación 
de estas dos gobernaciones destinó a Alonso de Ojeda y Diego de Nicuesa su conquista y colonización. Cuyo pensamiento no era distinto a su predecesor, tenía una gran ambición por del oro, esclavizar aborígenes y acumular riquezas.

Un gran bastión del Imperio Español en el Caribe era La Española de donde enviaron los pertrechos menester para iniciar las expediciones ordenadas por el monarca Fernando II de Aragón. Ojeda fundó San Sebastián de Urabá en 1810, sería el primer poblado establecido en Colombia. Ojeda muere para este mismo año en Santo Domingo en busca refuerzos dejando como sucesores a Vasco Núñez de Balboa, Francisco Pizarro y Martín Fernández de Enciso.

El primero terminó convirtiéndose en el gobernador de Darién, después de una disputa con Nicuesa quien sostenía que debía ser el gobernador porque el Darién estaba en la jurisdicción de Ojeda. La querella ulterior fue con Enciso que quería establecerse como líder de la ciudad, ya que de asentamiento se trocó en ciudad con la fundación del cabildo y en el primer asentamiento español permanente en nuestro continente, su nombre fue sustituido por el de Santa María la Antigua del Darién. Ambos levantamientos, tanto el de Nicuesa como el de Enciso, fueron mitigados por los seguidores de Balboa sin problemas mayores.

Balboa pasó a ser la máxima autoridad del Darién, tuvo alianzas con treinta caciques de las confinidades, cambió las relaciones y métodos que existían inicialmente con los aborígenes, el Darién se transformó en un pueblo en el que los españoles, aborígenes y niños mestizos podían convivir y finalmente para 1511, el rey Fernando II de Aragón lo reconoce como gobernador al haber recibido sus beneficios en oro. Este reconocimiento oficial no se prolongaría mucho tiempo, a causa del mito de El Dorado cuyo designio se le enquistó en el pensamiento a Balboa y debió recurrir ayuda, precisamente 500 hombres para su expedición terrestre, a La Española por medio de formalidades que solían hacérseles a los monarcas. Esto fue aprovechado por la conspiración orquestada por Enciso y fue asaz pernicioso para el líder del Darién, que 
desde este momento al igual que Colón, Ojeda, Cosa entre varios otros su sino empezó a rezumarse por los intersticios consustanciales por la codicia y la ambición humana. Ahora el protagonismo había sido cedido a Pedrarias Dávila, que se convirtió en el gobernador reciente del Darién, tan pronto como arribó a tierra firme a mediados de 1514 desarticuló toda la estructura de poder local e incoó precipitadamente el juicio de residencia contra Núñez de Balboa que termina en la horca en 1519. Es fundamental resaltar que en la misma Junta de Burgos, también se gesta, en 1511, las Leyes de Burgos, en las que el fraile dominico Antonio de Montesinos denuncia las condiciones sociales y los abusos a que eran sometidos los indígenas del Nuevo Mundo por parte de numerosos encomenderos de La Española.

El obispo Fray Bartolomé de las Casas esbozaba en sus memorias que entraban los españoles en los pueblos y no dejaban niños, ni viejos, ni mujeres preñadas que no desbarrigaran y hacían pedazos. Hacían apuestas sobre quién de una cuchillada abría un indio por medio o le cortaba la cabeza de un tajo. Tomaban las criaturas por las piernas y daban con ellas en las piedras. Añade de las Casas que incluso hacían unas orcas largas y de trece en trece, en honor de Jesucristo y los doce apóstoles, los quemaban vivos. Pues, los perros también se vieron involucrados en esto, apunta de las Casas que para mantener a los perros amaestrados en matar, traían muchos indios en cadenas y los mordían y los destrozaban, y tenían carnicería pública de carne humana, y les echaban los pedazos a los perros. Yo vi todo esto y muchas maneras de crueldad nunca vistas ni leídas acota el obispo.

En este orden de ideas, amén de catequizar y "civilizar" a los "infieles", refiriéndose a los aborígenes, se va desarrollando simultánea e inherentemente a estos dos rasgos, un tercero, el etnográfico. En el cual recoge Baltasar de Lodares un siglo más tarde las impresiones de los misioneros por un mundo distinto: "No formaban pueblo, ni reconocían rey ni cacique que les gobernase e impusiera leyes, en tal grado que ni los hijos guardaban obediencia a sus padres, ni respetaban el natural parentesco" (3). Posteriormente señala que "Tales observaciones, anotadas como testimonio misionero, 
debieron generar en éstos fuerte impresión, puesto que la forma de vida aborigen era contemplada nomás, desde la mirada europea, como vida salvaje", Vargas Arena (2010).

En lo que a la percepción del trabajo respecta, se vierten perspectivas opuestas de dos misioneros franciscanos el primero fray Miguel de Olivares quien estima que los aborígenes "Son tan flojos, perezosos y haraganes..., que por verse libres de las exigencias de los Misioneros, ..., huyen con mucha frecuencia en grupos numerosos a los montes, sin que tengan otro motivo para la fuga que éste de no querer trabajar..." Vargas Arena (2010), mientras que Pedro Manuel Arcaya Urrutia con mentalidad más abierta y objetiva intenta comprender la manera cómo se desenvuelven los indígenas explicando que éstos "Una vez satisfechas sus necesidades básicas dejaban de trabajar. No veían en el trabajo una fuente de enriquecimiento y acumulación de bienes, sino de satisfacción de sus necesidades", Vargas Arena (2010).Pedro Arcaya reconoce que era complejo para los conquistadores ibéricos entender esto.

Empero, debe reconocerse que ningún reinado instituido de Europa hasta entonces se había interesado por darle significación legal por medio de juntas conformadas por teólogos y juristas que sancionaban leyes acerca del trato que se les debía conceder a los aborígenes americanos.

Las leyes emanadas de la Junta de Burgos para "reivindicar" a los indígenas fueron complementadas posteriormente por otras, como las Ordenanzas aprobadas por la Junta de Valladolid en 1513, y la Junta de Madrid en 1516. Ciertamente estas leyes no pudieron evitar ni los abusos ni los vejámenes a los que fueron sometidos nuestros aborígenes, sin embargo, restringieron un poco a los encomenderos y, sobre todo, hicieron evidentes los límites que intentaba establecer la Corona.

En síntesis, se puede evidenciar por diversas fuentes que fueron miembros de la iglesia los primeros en alzar su voz tanto en las cortes conformadas en España donde sus principales actores eran juristas y teólogos, como por medio de misivas y memorias desde distintas latitudes de Nuestra América cuando éstos ejercían sus funciones, 
queriendo reivindicar a los aborígenes, partiendo de la comprensión de su estilo de vida, por cuanto de otra manera no pudiese haber reivindicación sino usurpación de un tipo de vida, costumbres, cánones, simbolismos e idiosincrasia.

\section{REFLEXIONES FINALES}

Por último se abordó la complexión de la sociedad española e india americana, donde se evidencia la diferencia que existía entre ellas y que después debió unificarse, mas no en todos los aspectos, aún en la actualidad hay resistencia por sus símbolos y reclamos de espacios ancestrales, aunado a lo planteado por Briceño Briceño (2019), quien plantea que las comunidades guardan información histórica que debe ser puesta a la palestra pública como elemento ejemplificador de la descolonización de los saberes como parte de una independencia objeto de la educación permanente a la cual se debe empoderar la ciudadanía.

Siendo este un factor expuesto por Alemán Sangronis (2019), cuando hace énfasis en la necesidad de articular la descolonización como un aspecto transversal para la conformación de una cultura pensada desde otra mirada no colonialista en la historia latinoamericana, esto implica repensar la narrativa histórica donde Wagner (2017), argumenta que se vive una confrontación entre la reedición de la historia o un final epocal, visión dialéctica necesaria para conformar una posición reflexiva necesaria para la comprensión del valor de la historia como elemento fundamental para el crecimiento sistémico de la sociedad, siendo esta una opción para la estructuración de una democracia participativa en conjugación con lo expuesto por Smith Quiñones (2017), al indicar la justa necesidad de promover una participación protagónica de las personas en aras de construir una historia en consonancia con sus reales valores sociales ancestrales, siendo esto desde la perspectiva de Rodríguez (2019), la posibilidad de emplear una filosofía emergente como medio epistémico en favor de sustentar los constructos teóricos - sociales que puedan compaginarse en la generación de un 


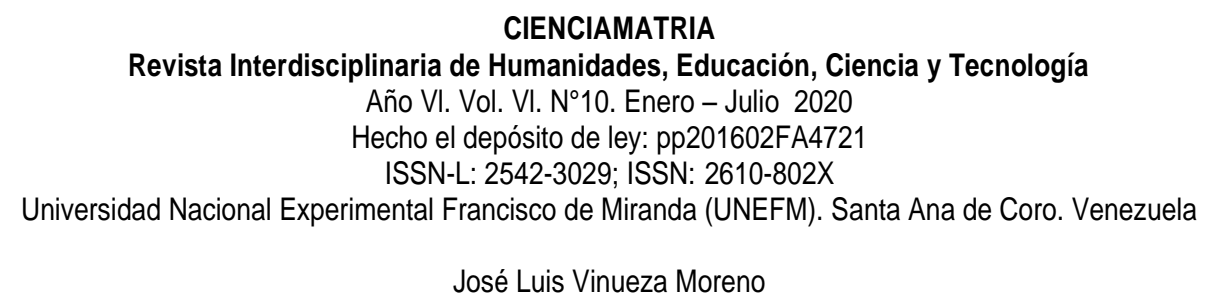

imaginario colectivo en favor de promover una identidad en conjugación de concatenar la promoción de una autentica visión histórica latinoamericana.

\section{REFERENCIAS CONSULTADAS}

1. Alemán Sangronis, J. (2019). Descolonización del hacer investigativo para la Regeneración Social Venezolana. CIENCIAMATRIA, 5(9), 187 - 198. https://doi.org/10.35381/cm.v5i9.112

2. Brizuela, J. C. (2013). Las misiones capuchinas en los Llanos venezolanos. Apuntes para el estudio de San Carlos de Austria (1658-1787). Alcaldía Municipio San Carlos, Estado Cojedes, Venezuela.

3. Briceño Briceño., J. (2019). Una mirada geohistórica a la comunidad de Chiquiao, Estado Trujillo desde la etnografía. CIENCIAMATRIA, 5(9), 130 - 150. https://doi.org/10.35381/cm.v5i9.103

4. Malamud, C. (2010). Historia de América. Alianza Editorial: España.

5. Rodríguez, A. (2019). Desde la filosofía hacia el pensamiento emergente en el desarrollo de los procesos investigativos. Revista Arbitrada Interdisciplinaria Koinonía, 4(7), 262-279. doi:http://dx.doi.org/10.35381/r.k.v4i7.204

6. Vargas Arena, I. (2010). Mujeres en tiempos de cambio. Colección Bicentenario. Caracas, Venezuela.

7. Smith Quiñones., P. (2017). Democracia participativa desde una concepción transmoderna y descolonial. Revista Arbitrada Interdisciplinaria Koinonía, 2(3), 131-144. Recuperado de http://fundacionkoinonia.com.ve/ojs/index.php/revistakoinonia/article/view/56/43

8. Wagner, J. (2017). El cambio histórico de época o el renacer del fin de la historia. La confrontación en nuestrámerica. CIENCIAMATRIA, 3(5), 71-94. Recuperado a partir de http://cienciamatriarevista.org.ve/index.php/cm/article/view/14 


\author{
CIENCIAMATRIA \\ Revista Interdisciplinaria de Humanidades, Educación, Ciencia y Tecnología \\ Año Vl. Vol. VI. №10. Enero - Julio 2020 \\ Hecho el depósito de ley: pp201602FA4721 \\ ISSN-L: 2542-3029; ISSN: 2610-802X \\ Universidad Nacional Experimental Francisco de Miranda (UNEFM). Santa Ana de Coro. Venezuela \\ José Luis Vinueza Moreno
}

\title{
CONSULTED REFERENCE
}

1. Alemán Sangronis, J. (2019). Descolonización del hacer investigativo para la Regeneración Social Venezolana. CIENCIAMATRIA, 5(9), 187 - 198. https://doi.org/10.35381/cm.v5i9.112

2. Brizuela, J. C. (2013). Las misiones capuchinas en los Llanos venezolanos. Apuntes para el estudio de San Carlos de Austria (1658-1787). Alcaldía Municipio San Carlos, Estado Cojedes, Venezuela.

3. Briceño Briceño., J. (2019). Una mirada geohistórica a la comunidad de Chiquiao, Estado Trujillo desde la etnografía. CIENCIAMATRIA, 5(9), 130 - 150. https://doi.org/10.35381/cm.v5i9.103

4. Malamud, C. (2010). Historia de América. Alianza Editorial: España.

5. Rodríguez, A. (2019). Desde la filosofía hacia el pensamiento emergente en el desarrollo de los procesos investigativos. Revista Arbitrada Interdisciplinaria Koinonía, 4(7), 262-279. doi:http://dx.doi.org/10.35381/r.k.v4i7.204

6. Vargas Arena, I. (2010). Mujeres en tiempos de cambio. Colección Bicentenario. Caracas, Venezuela.

7. Smith Quiñones., P. (2017). Democracia participativa desde una concepción transmoderna y descolonial. Revista Arbitrada Interdisciplinaria Koinonía, 2(3), 131-144. Recuperado de http://fundacionkoinonia.com.ve/ojs/index.php/revistakoinonia/article/view/56/43

8. Wagner, J. (2017). El cambio histórico de época o el renacer del fin de la historia. La confrontación en nuestrámerica. CIENCIAMATRIA, 3(5), 71-94. Recuperado a partir de http://cienciamatriarevista.org.ve/index.php/cm/article/view/14

C 2020 por el autor. Este artículo es de acceso abierto y distribuido según los términos y condiciones de la licencia Creative Commons Atribución-NoComercial-Compartirlgual 4.0 Internacional (CC BY-NC-SA 4.0) (https://creativecommons.org/licenses/by-nc-sa/4.0/). 